\title{
Moderating effects of socio-cultural values on pro-environmental behaviors
}

Purpose - This paper aims to explain the discrepancy between pro-environmental intentions and behaviors with moderating effects of two socio-cultural values (espoused individualism and faith in others) on the link between intentions and actual behaviors to save electricity.

Design/methodology/approach - An online survey of 303 consumers in Hong Kong with a structured questionnaire was used to collect the data to test all the hypothesized relationships.

Findings - Attitude toward saving electricity has a significant positive effect on the intentions to save electricity but subjective norms and perceived behavioral control have no such effect on intentions but do positively affect the actual electricity saving behavior.

Finally, the link between intentions and behavior to save electricity is negatively moderated by espoused individualism and positively by faith in others.

Research limitations/implications: This study was conducted with a sample of consumers in Hong Kong, hence its findings may not be generalizable to other countries.

Originality/value - This study provides new insights into the link between pro-environmental intentions and behaviors by looking beyond the theory of planned behavior and exploring the moderating role of socio-cultural values on the intention-behavior link.

Keywords: attitude, espoused individualism, faith in others, pro-environmental, perceived behavioral control, subjective norms

Paper type: Research paper 


\section{Introduction}

The world is facing many serious environmental problems today, such as the greenhouse effect, global warming, urban air pollution, and scarcity of safe drinking water; and most of these are arguably results of human actions and exploitation of our environment over time (Vlek and Steg, 2007). However, it is believed that taking corrective and preventive actions may still save the environment from further degradation. These actions are generally called as pro-environmental or green behaviors, which refers to an individual's activities in regulating or reducing the use of scarce or harmful resources, such as electricity, water, petrol, and pesticides, etc. (Neale and Fullerton, 2010).

While governments, organizations and individuals are all responsible for mitigating further environmental damage, the crucial role which consumers could play in such mitigation should not be neglected (Dietz et al., 2009). Indeed, across various behavioral contexts such as shopping for green products (Khare, 2015; Nguyen et al., 2017) and paying more for these products (Trivedi et al., 2015), there is growing evidence that most consumers do not behave alongside their reported favorable attitude or intentions toward environmental protection. On the other hand, when compared with that to green product purchase and consumption, research attention paid to consumer engagement in sustainable behaviors related to reducing waste and food consumption, and saving energy and water is relatively scant (Thieme et al., 2015). 
Early research on pro-environmental behavior often employed the theory of planned behavior (TPB) to explore the impact of consumers' attitude, subjective norms and perceived behavioral control ${ }^{1}$ on the corresponding intentions and actual behavior (e.g., Han et al., 2010; Kalafatis et al., 1999; Tonglet et al., 2004; Wu and Chen, 2014). However, these studies found mixed results with some of them showing that all the three core components of TPB (i.e., attitude, norms and control) together influence consumers' pro-environmental intentions and behavior, whereas others show that only one or two of these have an impact in certain conditions. Thus, there is still no consensus on the impact of attitudes, subjective norms and perceived behavioral control on pro-environmental intentions and behavior.

For instance, Han et al. (2010) show that attitude, norms and control have significant positive influences on the corresponding intentions and behavior. Wu and Chen (2014) also report similar influences in their study of green purchase. These researchers also observed no significant difference in the strength of these influences between customers who actively practice eco-friendly activities and those who do not. In contrast, Kalafatis et al. (1999) demonstrated that TPB is more apt to explain the behavior of consumers in more (e.g., UK) rather than less developed economies (e.g. Greece). Similarly, Tonglet et al. (2004) revealed that only attitude (but not norms or control) has a significant effect on intentions to recycle.

\footnotetext{
${ }^{1}$ Consumer attitude, subjective norms, perceived behavioral control, behavioral intentions and actual behavior are referred to as attitude, norms, control, intentions and behavior respectively, throughout this manuscript in order to save space and to maintain consistency.
} 
Researchers subsequently tried to address these inconsistent results by adopting an alternative theoretical perspective such as the national cultural values framework (Hofstede, 1980; 1991, 2001), but these studies found mixed results. For example, Chan and Lau (2001) found stronger influences of norms and control on green purchase intentions among Chinese (vs. American) consumers. Conversely, they observed a stronger influence of intentions on behavior among American rather than Chinese consumers in the same study. Similarly, Soyez (2012) found that ecocentric value orientation is more salient for consumers from individualistic cultures (e.g., USA), whereas an anthropocentric value orientation is more salient for those from collectivistic cultures (e.g., Russia). In the same study, he also found no empirical support for the hypothesized influence of the national cultural value, 'assertiveness', in both individualistic and collectivistic cultures. In addition, similar mixed findings were reported in other investigation with consumers in Hong Kong (Li, 1997).

One of the reasons for these mixed findings could be that most of these studies operationalize culture at a national level by comparing the strengths of their hypothesized relationships across consumer samples from different countries, an approach that has been criticized for the problem of 'ecological fallacy' (Sharma, 2010). Specifically, relying on national cultural scores for individual-level comparison assumes that all people from a country share similar cultural values and ignores their within-group variance. As a result, most of these studies use popular national cultural values (e.g., individualism/collectivism) to 
test their impact on green behavior and ignore individual-level cultural values such as espoused individualism (EIND). Similarly, Berger and Corbin (1992) showed that faith in others (FIO) moderates the strength and form of the link between attitude and support for regulatory measures to promote environmentally responsible behavior but despite such evidence about the moderating effect of FIO on the attitude-behavior link, its moderating role has been largely ignored in subsequent research.

We address all the above research gaps in this paper by studying the moderating effects of two individual-level socio-cultural values, EIND and FIO, on the link between proenvironmental intentions and behavior. We test our hypotheses in the context of saving electricity with a sample of 303 consumers in Hong Kong. We find that attitude toward saving electricity has a significant positive effect on the intentions to save electricity but subjective norms and perceived behavioral control have no such effect. Perceived behavioral control and intentions to save electricity also positively affect the actual behavior to save electricity. Moreover, the intention-behavior link is negatively moderated by EIND and positively by FIO. We discuss the conceptual contribution and managerial implications of these findings along with their limitations and future research directions.

\section{Theoretical background and hypotheses development}

The paper aims to investigate the factors that would influence individuals' electricity consumption. Drawing upon the literature on TPB and individual-level socio-cultural values, 
it explores the boundary conditions accountable for the incongruence between intentions to save electricity (ISE) and actual behavior in saving electricity (BSE), by examining the moderating effects of EIND and FIO on the ISE-BSE link. This section reviews the relevant literature and develops specific hypotheses and conceptual model for this study. Theory of planned behavior (TPB) and green behavior Theory of planned behavior (Ajzen, 1991) has been regarded as one of the most influential models to explain different kinds of human behavior (e.g., Han et al., 2010; Litvine and Wustenhagen, 2011), in particular, those concerning environmental protection such as energy saving and green purchase (e.g., Han and Stoel, 2017). The model is an extension of the theory of reasoned action with the incorporation of perceived behavioral control as an additional determinant of behavioral intention (Ajzen, 1991). In essence, TPB posits that an individual's performance of a particular behavior depends on his/her intentions to perform that behavior, which, in turn, is a function of that person's relevant attitude, subjective norms and perceived behavioral control (Ajzen, 1991). Within this context, attitude refers to one's overall evaluation of the focal behavior, whereas subjective norms and perceived behavioral control respectively refer to one's perceived social pressure and ease to perform the focal behavior (Armitage and Conner, 2001). TPB also posits a direct effect of control on actual behavior (Ajzen, 1991). Recent meta-analyses confirm the robustness of TPB in explaining socially responsible consumption behaviors (Han and Stoel, 2017). 
Influence of attitude toward saving electricity (ASE)

Within the context of TPB, attitude refers to a person's overall positive or negative evaluation of performing the focal behavior. It is also generally believed that the more favorable the attitude toward behavior is, the stronger the behavioral intentions will be (Ajzen, 1991). Prior pro-environmental research also reported that attitude is an independent predictor of the corresponding behavioral intentions (Bamberg and Moser, 2007; Steg et al., 2014). Hence,

H1: Attitude toward saving electricity positively influences intentions to save electricity. Influence of subjective norms toward saving electricity (SNSE)

Subjective norms reflect an individual's perceived social pressure to perform a certain behavior (Ajzen, 1991). In numerous green studies, pro-environmental social norms are shown as independent predictors of the correspondent intentions (Bamberg and Moser, 2007; Chan and Lau, 2001). Prior research on energy saving behavior also reported a positive correlation between social influence and this behavior (Gadenne et al., 2011). Therefore, H2: Subjective norms toward saving electricity positively influences intentions to save electricity.

Influence of perceived behavioral control over saving electricity (PBCSE)

Perceived behavioral control refers to the extent of control that an individual perceives over performing a certain behavior (Kang et al., 2006). It is concerned with a person's perceived ease or difficulty to perform the focal behavior and such perception is subject to influence of 
both internal (e.g., own ability) and external factors (e.g., environmental constraints) (Ajzen, 1991). Prior research on green behavior consistently reported a positive influence of perceived behavior control on the corresponding behavioral intentions (e.g., Ajzen, 1991; Chan and Lau, 2001). In a similar vein, more recent studies also revealed that perceived inconvenience and barriers significantly deters intentions to purchase green products (Barbarossa and de Pelsmacker, 2016; Trivedi et al., 2015). Given that saving electricity involves personal inconvenience and discomfort (e.g., use less air-conditioning or hot water) as well as a certain amount of environmental knowledge for practicing this behavior (Wang et al., 2011; 2017), individuals are unlikely to have full volitional control over it. Hence, based on Ajzen's (1991) postulation, perceived behavioral control should serve as a significant driver of behavioral intentions (see also Nguyen et al., 2017). Accordingly,

H3: Perceived behavioral control over saving electricity (PBCSE) positively influences intentions to save electricity (ISE).

In addition to an effect on behavioral intention, perceived behavioral control can have a direct effect on actual behavior when the focal individuals are accurate in their evaluation of actual behavioral control (Ajzen 1991; McCarty and Shrum, 1994). Thus,

H4: Perceived behavioral control over saving electricity (PBCSE) positively influences actual behavior in saving electricity (BSE). 
Intentions refers to an individual's disposition to perform a certain behavior and whether the behavior can be performed depends much on the relative strength of the disposition (Ajzen, 1991). The same relationship is evident in Chan's $(1999,2000,2001)$ and Thieme et al.'s (2015) studies concerning green behavior. Indeed, prior research based on the theory of reasoned action or TPB consistently revealed that behavioral intentions serves as a proximal and significant determinant of the corresponding actual behavior (Ajzen, 1991). Therefore,

H5: Intentions to save electricity positively influence actual behavior in saving electricity.

\section{Consumers' green intention-behavior gap}

Despite TPB's general robustness to explain pro-social (e.g., pro-environmental) behavior, mixed findings about the impact of attitudes, subjective norms and perceived behavioral control on pro-environmental intentions and behavior, suggest that the explanatory power of TPB may be further improved if appropriate variables (e.g., mediators or moderators) could be incorporated. This view echoes those of other researchers interested in applying TPB to explain pro-environmental behavior by incorporating constructs, such as moral norms (de Leeuw et al., 2014; Wang et al., 2016), self-identity (Bamberg and Moser, 2007; Klockner, 2013) and environmental concern (Hustvedt and Dickson, 2009; Tan et al., 2017) into their analysis. Relating specifically to investigating energy saving behavior, researchers tried to improve the explanatory power of TPB by incorporating such variables as price, policy and 
propaganda, environmental concern, environmental knowledge, moral norms, past behavior, and various demographic characteristics (Tan et al., 2017; Wang et al., 2011, 2017).

Most of these studies treat the additional variables as antecedents of intentions and/or behavior, which is useful to understand what other variables besides the core TPB elements (i.e., attitude, subjective norms and control) may directly influence intention and behavior. The oft-cited low correspondence between intentions and behavior remains largely unexplored. Specifically, past studies on green behavior, often find the expressed willingness to act green and the actual green behavior incongruent with each other (Follows and Jobber, 2000; Chan, 2001, 2004; Moisander, 2007). This incongruence, among others, highlights the need for further investigation to explore factors that may facilitate or inhibit the translation of behavioral intentions into the corresponding actual behavior.

In this context, prior researches suggest that individual-level factors such as in-group identity, expectation of others' cooperation and efficacy, and self-identification with environment-friendly traits are significant in differentiating between 'non-green' and 'green' buyers (Gupta and Ogden, 2009; Khare, 2015). Similarly, Han and Stoel (2017) call for more research on potential moderators of the intention-behavior link to improve the explanatory power of the model. This study extends the growing research on this topic by exploring the moderating effects of two individual-level socio-cultural factors (EIND and FIO) on the intention-behavior link for saving electricity. 
Espoused cultural values and green behavior

Researchers recommend the use of individual-level cultural values to investigate the impact of culture on personal behavior (e.g., Sharma, 2010; Nguyen et al., 2017), which has led to the concept of "espoused cultural values" to elucidate individual-level cultural values (e.g., Srite and Karahanna, 2006). This view of cultural values suggests that national culture manifests itself through an individual's espoused cultural values, which represent "the degree to which an individual embraces the values of his/her national culture" (e.g., Srite and Karahanna, 2006, p. 681). Although these espoused measures were employed to explain ITrelated usage behavior (e.g., Srite and Karahanna, 2006), their application to explain green behavior is rare. We address the above gap by exploring the moderating effect of espoused individualism (EIND) on the intentions-behavior link in the context of saving electricity.

EIND captures an individual's tendency to subordinate his/her individual interests in pursuit of group interests (Srite and Karahanna, 2006) with the less individualistic (or more collectivistic) people being expected to be more willing to advance group interests even at the expense of their personal interests (Chan, 2001). EIND should be relevant to an individual's green behaviors because it may result in costs/inconvenience to him/her but benefits to the public at large. Besides, among Hofstede's (1980) four core cultural dimensions, individualism/collectivism is often singled out by researchers to explore the impact of culture on green behavior (e.g., McCarty and Shrum, 1994; Li, 1997). 
Moderating effect of espoused individualism/collectivism (EIND)

Drawing on Hofstede's (1980) cultural concepts, previous studies often treated a person's level of individualism/collectivism as a moderator and examined how it would alter the direct influence of other determinants on behavioral intentions or actual behavior within various non-green behavioral contexts (e.g., Ali et al., 2019; Du et al., 2017; Srite and Karahanna, 2006). Although some of these studies might not explicitly use the term 'espoused' individualism or collectivism, they often posited that individuals bearing high levels of individualism (i.e., less collectivistic) are less willing to sacrifice their personal interests in pursuit of public good as they do not place high priority on group interests or cohesiveness (Sharma, 2010). On the other hand, it is noted that the performance of green behavior often results in personal costs and inconvenience to the focal actor but benefits to the public at large (Chan, 2010). Overall, the foregoing studies suggest that an individualistic actor may be more hesitant to act green even if he/she has expressed his/her intentions to do so. This is because when it comes to actual action, the higher EIND will prompt the person to be more alert of the personal sacrifices associated with the action, which in turn could hamper the effectiveness in translating the behavioral intentions into the corresponding behavior. Thus, H6: Espoused individualism negatively moderates (weakens) the positive influence of intentions to save electricity and actual behavior in saving electricity.

Moderating effect of faith in others (FIO) 
According to Berger and Corbin (1992), faith in others (FIO) is defined as an individual's perception of the efficacy of others (e.g., governments, companies) to perform the desired behavior. It could be conceived as the opposite of perceived self-efficacy which refers to an individual's perception of his own ability to perform the desired behavior (Parkinson et al., 2017). In the literature, it is observed that perceived self-efficacy or constructs bearing similar notions (e.g., perceived consumer effectiveness and even perceived behavioral control) have often been taken into consideration when examining factors that influence green behavior (Ajzen, 1991; Berger and Corbin, 1992). Despite such interest in applying the concept of perceived self-efficacy and the like to investigate green behavior, their interest in examining the influence of FIO within the same behavioral domain is scant. An exception of this is Berger and Corbin's (1992) investigation, which examined the moderating effect of an individual's FIO on the relationship between his/her environmental concern and support for others' involvement in pro-environmental activities (i.e., support behavior). They found that an individual's FIO strengthens the link between his/her environmental concern and support behavior. Hence, we expect FIO to moderate the intention-behavior link.

So far ecologically-responsible consumption of electricity is concerned, it is common to see individuals exhibit hesitation to engage in such consumption if they perceive other groups in society (e.g., the government, big business) shirk their responsibility to do the same. This perception would be even more salient if these other groups are regarded as possessing more 
resources (financial and technological) to deal with the related pollution, for instance, the government and big business. From another perspective, it may be argued that amidst the global trend of continued soaring environmental awareness across various sections in society (Chan and Lau, 2001), an individual who is faithful in others' ability to perform green behavior may already unconsciously assume that they will perform it either out of free will or social pressure. With this assumption, the individual may then be more motivated to convert his own green intentions into actual green behavior. This is so as the individual may now believe that his/her own efforts, together with those of others, will have a much higher chance to achieve his/her desired goal of a greener living environment. In a way, this inference is consistent with Vroom's (1964) expectancy theory which posits that people will be more motivated to behave in a particular way if they expect that their efforts will result in attainment of the desired goal. In sum, the above discussion suggests that individuals with higher levels of FIO would be more willing to realize their green intentions through action.

H7: Faith in others (FIO) positively moderates (strengthens) the positive influence of the intentions to save electricity on the actual behavior in saving electricity.

Figure 1 shows the conceptual model and summarizes all the hypotheses.

$<$ Insert figure 1 about here $>$

\section{Methodology}

Sample and Procedure 
In order to further verify the conceptual model, we first conducted in-depth interviews with thirteen Hong Kong residents with different socio-demographic backgrounds, in terms of age, gender, education, household income and occupation, to further explore the factors that may affect their electricity saving behavior. While these interviewees used somewhat different wordings to describe determinants of their saving behavior, what they described was largely covered by the constructs proposed in the conceptual model. These interviews provided further corroborative evidence to the validity of our proposed model and hypotheses. The proposed model was tested using data collected from an online survey in Hong Kong, using Survey Monkey.com ${ }^{\mathrm{TM}}$, with 303 valid replies. The target population consists of all Hong Kong Chinese residents aged from 18 to 65 years who are regular users of electric lightings, home entertainment, computers, electric water heaters, and air-conditioners. Two reminders were sent to potential respondents to encourage participation. The demographic profile of the sample is similar to the overall Hong Kong population except for the age and income distribution (Hong Kong Monthly Digest of Statistics, 2019).

\section{Measures}

The survey used two questionnaires; first tapped the participants' attitude, norms, control, intentions, EIND and FIO measures as well as some demographic questions, and the second sent out one month later to the same participants, captured actual electricity saving behaviors. 
We used this design to overcome common method bias and other potential problems associated with survey method. All the measures were adapted from existing well-established scales. For example, ASE, SNSE, PBCSE and ISE scales were adapted from past studies using the theory of reasoned action and TPB (e.g., Ajzen 1991, Chan and Lau 2001). EIND scale was adapted from Srite and Karahanna (2006) and FIO scale from Berger and Corbin (1992), which has long been used extensively in recent research on pro-environmental behaviors (e.g., D'Souza et al. 2015; Jayawardhena et al., 2016). Finally, we used green advice from Hong Kong Environmental Protection Department (2014) and items from Straughan and Roberts (1999) to capture the participants' actual behavior to save electricity (BSE) for five common electrical appliances.

The questionnaire was first developed in English, and then subsequently translated into Chinese to ease local respondents' comprehension. Back-translation technique was also applied to check for its linguistic equivalence. The questionnaire was pretested with a group of 30 individuals to identify ambiguous wording or questions, and a few Chinese phrases were modified based on the pre-test feedback for the benefit of clarify. Hence, the questionnaire was modified based on the feedback from the pre-test. Table I shows all the scale items and their descriptive properties.

$$
<\text { Insert Table I about here }>
$$

\section{Data analysis and results}


We first performed Confirmatory factor analysis (CFA) using AMOS 22.0 to validate all the scales. Overall, the measurement model shows a close fit with all the fit indices $\left(\chi^{2}=620.53\right.$;

$\left.d f=351, \chi^{2} / d f=1.77 ; \mathrm{RMSEA}=.051 ; \mathrm{SRMR}=.048 ; \mathrm{CFI}=.95 ; \mathrm{AGFI}=.90 ; \mathrm{NNFI}=.90\right)$

near to the acceptable cut-off limits recommended by Hair et al. (2010). All the factor

loadings are significant $(p<.05)$ and all the average variances extracted (AVEs) exceed .50.

Moreover, the composite reliabilities of all the constructs are above .60 (Bagozzi and Yi,

1988). These results support convergent validity (Hair et al. 2010). Next, the AVE values for

all the constructs are higher than their squared correlations with all the other constructs,

which confirms discriminant validity (Fornell and Larcker, 1981). Table II shows the

correlations matrix with composite reliabilities and other descriptives for all the constructs.

$<$ Insert Table II about here $>$

Next, we used a structural model with the three independent variables (ASE, SNSE, and PBCSE), two moderators (EIND and FIO), mediator (ISE), and interaction terms for ISE with EIND and FIO with the dependent variable (BSE) to test all the hypotheses. We also included the participants' age, gender, educational and income as control variables. The structural model shows a close fit with all the fit indices $\left(\chi^{2}=12.37 ; d f=6, \chi^{2} / d f=2.06\right.$; RMSEA $=.042 ; \mathrm{SRMR}=.025 ; \mathrm{CFI}=.98 ; \mathrm{AGFI}=.95 ; \mathrm{NNFI}=.94)$ better than recommended values.

Table III presents a summary of these results.

$<$ Insert Table III about here $>$ 
All the three independent variables, $\operatorname{ASE}(\mathrm{H} 1: \beta=.58, p<.01)$, SNSE $(\mathrm{H} 2: \beta=.32, p$ $<.001)$ and PBCSE $(\mathrm{H} 3: \beta=.21, \mathrm{p}<.01)$ have significant influence on ISE. Thus, H1-H3 are all supported. Next, both PBCSE (H4: $\beta=.13, p<.05)$ and ISE (H5: $\beta=.25, p<.01)$ have significant effects on BSE, hence both H4 and H5 are also supported. Finally, both EIND*ISE $(\mathrm{H} 6: \beta=-.18, p<.05)$ and FIO*ISE $(\beta=.14, p<.05)$ interactions have significant negative and positive effects respectively, on BSE. Thus, $\mathrm{H} 6$ and $\mathrm{H} 7$ are also supported. No control variable (age, gender, education and income) has any significant influence on the other variables. Next, we discuss the implications of all these results.

\section{Discussion and implications}

Our findings suggest that ASE is the variable that exerts the strongest positive influence on ISE, which is consistent with Ajzen (1991) and previous empirical research of a similar kind (e.g., Han et al., 2010). These findings remind the Hong Kong government and green groups of the importance to enhance the positive attitude among residents through proper civic education and pro-environmental promotion. Marketers can focus on reinforcing consumer attitudes toward the corresponding energy consumption behavior in their marketing communications campaigns. Next, SNSE also has a significant positive effect on ISE, which matches the premise of TPB (Ajzen, 1991) and past research (e.g., Kalafatis et al., 1999; Lee, 2011). However, this effect is relatively weaker possibly as the participants of our study consist of a relatively higher percentage of young and middle-aged adults who may be less 
susceptible to the influence of their significant referents, a point that may be corroborated by their relatively high average EIND score (4.46 out of 7). As such, they may be less concerned about if their electricity usage is socially approved by these referents or not. Moreover, for Hong Kong people, the behavior of saving electricity may not be a top concern in daily life, therefore, individuals may not be able to tell accurately what their significant referents think in relation to their behavioral intentions to save electricity.

Next, echoing the premise of TPB (Ajzen, 1991) and empirical findings of other TPBbased research on green behavior (Karim et al., 2013; McCarty and Shrum, 1994), the present study also reveals that PBCSE has a positive effect on ISE. However, this effect is weakest among the three TPB variables possibly due to the group-use situation and congested living environment in Hong Kong that may limit individuals' volitional control over the use of airconditioning, thus hindering their intentions to save energy. Similar results are reported by others on the adverse impact of living conditions (Tanner and Kast, 2003). Second, to possess the related volitional control, individuals need to invest in their knowledge, skills, effort and time (Hartmann and Apaolaze-Ibanez, 2012; Scarpa and Willis, 2010). They also need to be motivated by factors such as financial resources before forming their behavioral intentions (Ajzen, 1991). Therefore, it is essential for policy makers, environmental groups, and green marketers to provide the public with sufficient information relating to the monetary benefits 
of using electricity-saving products. Furthermore, they are recommended to provide the households with financial incentives as encouragement.

Next, consistent with empirical findings from prior green behavior research based on TPB (Chan, 2001; Chan and Lau, 2001), both ISE and PBCSE in this study are found to exert significant direct positive effects on BSE. However, these effects are not too strong, which suggests that there is still much room for improvement in converting ISE and PBCSE into actual electricity saving behavior. These findings further highlight the policy and strategic importance to strengthen these links, possibly through public awareness and education programs through mass and social media. To further facilitate individuals' engagement in actual electricity saving behavior, policy makers should act more proactively to strengthen the infrastructural support for such engagement. Specifically, relevant officials should take the lead to work more closely with electricity suppliers and various built environment stakeholders (e.g., property developers, construction companies) to seek ways to expedite green building adoption. Similarly, these officials should do the same with manufacturers of electrical appliances to ensure that quality and energy-efficient appliances of various kinds are widely available to cater for customers' increasing energy saving need.

Next, EIND negatively moderates (weakens) the intention-behavior relationship, as hypothesized, which is consistent with other empirical findings about the moderating effect of EIND (Yung and Totten, 2012). Interestingly, even in a collective society such as Hong 
Kong (Hofstede and Hofstede, 2014), Hong Kong people who possess high EIND (mean score $=4.46)$ are inclined to behave more individualistically when it comes to making their decisions to take steps towards saving electricity. However, this effect is not very strong, possibly because even though Hong Kong people are relatively more individualistic, they are still influenced by the traditions of the collectivist culture that they grow up with in Hong Kong and need to navigate through in their daily activities.

Finally, FIO has a significant positive moderating effect on the relationship between ISE and BSE, which matches the findings of Berger and Corbin (1992). However, this effect is not very strong, possibly because faith in others is not likely to be as strong as individualism as a driver of individual behaviors. This finding also implies a lack of immediate government policy to control the abuse of electricity (Hong Kong Night Sky Brightness Monitoring Network, 2013; Green Sense, 2015) and long-term policy to facilitate science and technology's research and development in the area. Regulation, taxation, and electricitysaving schemes with strong financial incentives should be introduced to the general public and business to reduce their use of electricity.

Overall, these results make a significant conceptual contribution by not only offering empirical support to the basic tenets of the theory of planned behavior but by also extending its use to study green behaviors by incorporating EIND and FIO as moderators of the intention-behavior link. This study complements previous studies on energy saving behaviors 
among Chinese people by incorporating cultural values at the individual level. Notably, the findings in the present study contribute to the literature by identifying the unique role of EIND in Hong Kong. It is hoped that these insights will provide a basis for further in-depth investigation into the green behavior of Hong Kong people and Chinese.

Besides its conceptual contribution, this study also offers important managerial implications. Specifically, in order to increase Hong Kong people's awareness about saving electricity, the government could highlight the long-term benefits of energy saving and the adverse effects of abuse and over-consumption of electricity. Most importantly, it is essential to change people's dependence on air conditioning and the respective usage habit as it is shown that Hong Kong people want to feel cool immediately after walking into a room (Green Sense, 2015). More financial support could be granted to universities and technology firms to develop energy-saving equipment for use by households and firms. Green marketers should also carefully rework their brand image and act as socially responsible corporations.

Last, as mentioned, all the four demographic control variables are found to have no significant effects in this study. This result echoes various prior investigations that reported no significant effect of any demographic factors (e.g., Bartels and Onwezen, 2014; Evans et al., 2011; Straughan and Roberts, 1999). Given the inconsistent findings derived from previous studies, meta-analyses further concluded that it is very difficult to meaningfully relate green values or behavior to demographic profile (e.g., Diamantopoulos et al., 2003). In 
short, all these literatures suggest the potential to explore other non-demographic factors to explain green behavior, as the approach adopted in this study.

\section{Limitations and future research}

This study has a few limitations that future research may address. First, electricity usage may vary according to the season, hence future research should control for the seasonal effect.

Second, the findings may be influenced by individuals' perceived lack of knowledge, resources and opportunities to save electricity. Hence, future studies could include all these variables as potential moderators. Third, the present study is based on a survey approach. While this quantitative approach enables the test of a relatively parsimonious TPB-based model in a statistically rigorous manner, some other factors that may affect the process underlying individual energy saving behavior may still leave unexplored here. To rectify this limitation, future investigation based on comprehensive in-depth interviews should be conducted to further explore if there exist other possible intricate factors that would influence the process. This qualitative investigation would help validate the present findings as well as provide valuable input to fine-tune the proposed model. Finally, future studies could test the generalizability of our conceptual model by using it to explore other green behaviors (e.g., water saving, reducing food consumption or waste) across different geographic locations.

\section{References}

Ajzen, I. (1991), "The theory of planned behavior", Organizational Behavior and Human Decision Processes, Vol. 50 No. 2, pp. 179-211. 
Armitage, C.J. and Conner, M. (2001), "Efficacy of the theory of planned behavior: a metaanalytic review”, British Journal of Social Psychology, Vol. 40, pp. 471-499.

Bagozzi, R.P. and Yi, Y. (1988), "On the evaluation of structural equation model", Journal of Academy of Marketing Science, Vol 16, No. 1, pp. 74-94.

Bamberg, S. and Moser, G. (2007), "Twenty years after Hines, Hungerford, and Tomera: a new meta-analysis of psycho-social determinants of pro-environmental behavior", Journal of Environmental Psychology, Vol. 27 No. 1, pp. 14-25.

Barbarossa, C. and de Pelsmacker, P. (2016), "Positive and negative antecedents of purchasing eco-friendly products: a comparison between green and non-green consumers", Journal of Business Ethics, Vol. 134, No. 2, pp. 229-247.

Bartels, J., and Onwezen, M. C. (2014). "Consumers' willingness to buy products with environmental and ethical claims: the role of social representations and social identity", International Journal of Consumer Studies, Vol. 38, No. 1, pp. 82-89.

Berger, I.E. and Corbin, R.M. (1992), "Perceived consumer effectiveness and faith in others as moderators of environmentally responsible behaviors", Journal of Public Policy and Marketing, Vol. 11, No. 2, pp. 79-89.

Chan, R.Y.K. (1999), "Environmental attitudes and behavior of consumers in China: survey findings and implications”, Journal of International Consumer Marketing, Vol. 11 No. 4, pp. 25-52.

Chan, R.Y.K. (2000), "The effectiveness of environmental advertising: the role of claim type and the source country green image", International Journal of Advertising, Vol. 19 No. 3, pp. 349-375.

Chan, R.Y.K. (2001), “Determinants of Chinese consumers' green purchase behavior”, Psychology and Marketing, 18 (4): 389-413.

Chan, R.Y.K. (2004), "Consumer responses to environmental advertising in China", Marketing Intelligence and Planning, Vol. 22 No. 4, pp. 427-437.

Chan, R.Y.K. and Lau, L.B.Y. (2001), "Explaining green purchasing behavior: a crosscultural study on American and Chinese consumers", Journal of International Consumer Marketing, Vol. 14 No. 2/3, pp. 9-40.

Diamantopoulos, A., Schlegelmilch, B. B., Sinkovics, R. R. and Bohlen, G. M. (2003), "Can socio-demographics still play a role in profiling green consumers? A review of the 
evidence and an empirical investigation", Journal of Business Research, Vol. 56, No. 6, pp. 465-480.

D'Souza, C., Gilmore, A. J., Hartmann, P., Apaolaza Ibanez, V., and Sullivan-Mort, G. (2015). Male eco-fashion: a market reality. International Journal of Consumer Studies, Vol. 39 No. 1, pp. 35-42.

de Leeuw, A., Valois, P., Morin, A. and Schmidt, P. (2014), "Gender differences in psychosocial determinants of university students' intentions to buy fair trade products", Journal of Consumer Policy, Vol. 37, pp. 485-505.

Dietz, T., Gardner, G.T., Gilligan, J., Stern, P.C. and Vandenbergh, M.P. (2009), "Household actions can provide a behavioral wedge to rapidly reduce US carbon emissions", Proceedings of the National Academy of Sciences, Vol. 106 No. 44, pp. 8452-8456.

Du, R., Liu, L., Straub, D.W. and Knight, M.B. (2017), “The impact of espoused national cultural values on innovative behavior: an empirical study in the Chinese IT-enabled global service industry”, Asia Pacific Business Review, Vol. 23, No. 3, pp. 354-372.

Evans, J. R., D’Souza, G., E., Collins, A., Brown, C. and Sperow, M. (2011), “Determining consumer perceptions of and willingness to pay for Appalachian grass-fed beef: an experimental economics approach", Agricultural and Resource Economics Review, Vol. 2, August, pp. 233-250.

Environmental Protection Department (2014) “Cut your electricity bills”, Available at: http://www.epd.gov.hk/epd/english/how help/tips_savearth/green tips_1.html (accessed 18 August 2017).

Follows, S.B. and Jobber, D. (2000), "Environmentally responsible purchase behavior: a test of a consumer model”, European Journal of Marketing, Vol. 34 No. 5/6, pp. 723-746.

Fornell, C. and Larcker, D.F. (1981), "Structural equation models with unobservable variables and measurement errors", Journal of Marketing Research, Vol. 18, No. 1, pp. $39-50$.

Gadenne, D., Sharma, B. and Tim Smith, D.K. (2011), “The influence of consumers' environmental beliefs and attitudes on energy saving behaviors", Energy Policy, Vol. 39 No. 12 , pp. $7684-7694$.

Green Sense (2015), "Cooling the earth on Sept 25, 2015 green sense HK no air con night", Available at: http://greensense.org.hk/en/2015/08/ (assessed 8 August 2019). 
Gupta, S. and Ogden, D.T. (2009), "To buy or not to buy? a social dilemma perspective on green buying”, Journal of Consumer Marketing, Vol. 26 No. 6, pp. 376-391.

Hair, J.F., Black, W.C., Babin, B.J., Anderson, R.E. and Tatham, R. (2010), Multivariate Data Analysis, Prentice Hall, Upper Saddle River, MJ.

Han, H., Hsu, L.T.J. and Sheu, C. (2010), “Application of the theory of planned behavior to green hotel choice: testing the effect of environmental friendly activities", Tourism Management, Vol. 31 No. 3, pp. 325-334.

Han, T-I and Stoel, L. (2017), "Explaining socially responsible consumer behavior: a metaanalytic review of theory of planned behavior", Journal of International Consumer Marketing, Vol. 29, No. 2, pp. 91-103.

Hartmann, P. and Apaolaza-Ibanez, V. (2012), "Consumer attitude and purchase intention toward green energy brands: the roles of psychological benefits and environmental concern", Journal of Business Research, Vol. 65, pp. 1254-1263.

Hofstede, G. (1980), “Culture’s Consequences: International Differences in Work-Related Values. Beverly Hills, CA: Sage Publications, Inc.

Hofstede, G. (1991), Cultures and Organizations: Software of the Mind, McGraw-Hill, London.

Hofstede, G. (2001), Culture's Consequences, Sage Publications, Thousand Oaks, CA.

Hofstede, G. and Hofstede, G. J. (2014), "Dimensions of national cultures", Available at: http://www.geerthofstede.com/dimensions-of-national-cultures (accessed on 20 April 2014).

Hong Kong Monthly Digest of Statistics (2019), Census and Statistics Department, Hong Kong, various issues. Available at: https://www.censtatd.gov.hk/hkstat/sub/so20.jsp (accessed on 23 December, 2019).

Hong Kong Night Sky Brightness Monitoring Network (2013), "The seriousness of light pollution in Hong Kong", Available at: http://nightsky.physics.hku.hk/the-seriouSNSEsof-light-pollution-in-hong-kong.php (accessed 29 April 2013).

Hustvedt, G. and Dickson, M.A. (2009), "Consumer likelihood of purchasing organic cotton apparel: influence of attitudes and self-identity", Journal of Fashion Marketing and Marketing, Vol. 13, No. 1, pp. 49-65. 
Jayawardhena, C., Morrell, K. and Stride, C. (2016). "Ethical consumption behaviors in supermarket shoppers: determinants and marketing implications", Journal of Marketing Management, Vol. 32 No. 7-8, pp. 777-805.

Kalafatis, S.P., Pollard, M., East, R. and Tsogas, M.H. (1999), “Green marketing and Ajzen's theory of planned behavior: a cross-market examination", Journal of Consumer Marketing, Vol. 16 No. 5, pp. 441-460.

Kang, H., Hahn, M., Fortin, D., Hyun, Y.J. and Eom, Y. (2006), "Effects of perceived behavioral control on the consumer usage intention of e-coupons", Psychology and Marketing, Vol. 23, No. 10, 841-864.

Karim, G. W.A., Rusli, I.F., Biak, D.R. and Idris, A. (2013), "An application of the theory of planned behavior to study the influencing factors of participation in source separation of food waste", Waste Management, Vol. 33, No. 5, pp. 1276-1281.

Khare, A. (2015), "Antecedents to green buying behavior: a study on consumers in an emerging economy", Marketing Intelligence and Planning, Vol. 33 No. 3, pp. 309-329.

Klockner, C.A. (2013), "A comprehensive model of the psychology of environmental behavior: a meta-analysis", Global Environmental Change, Vol. 23, No. 5, pp. 1028-1038.

Lee, K. (2011), “The green purchase behavior of Hong Kong young consumers: the role of peer influence, local environmental involvement, and concrete environmental knowledge", Journal of International Consumer Marketing, Vol. 23, No. 1, pp. 21-44.

Li, L.Y. (1997), "Effect of collectivist orientation and ecological attitude on actual environmental commitment: the moderating role of consumer demographics and product involvement”, Journal of International Consumer Marketing, Vol. 9, No. 4, pp. 31-53.

Litvine, D. and Wustenhagen, R. (2011), "Helping "light green" consumers walk the talk: results of a behavioral intervention survey in the Swiss electricity market", Ecological Economics, Vol. 70, pp. 462-474.

McCarty, J.A. and Shrum, L.J. (1994), "The recycling of solid wastes: personal values, value orientations, and attitudes about recycling as antecedents of recycling behavior", Journal of Business Research, Vol. 30, No. 1, pp. 53-62.

Moisander, J. (2007), “Motivational complexity of green consumerism”, International Journal of Consumer Studies, Vol. 31, No. 4, pp. 404-416. 
Neale, L. and Fullerton, S. (2010), "The international search for ethics norms: which consumer behaviors do consumers consider (un)acceptable?", Journal of Services Marketing, Vol. 24, No. 6, pp. 476-486.

Nguyen, T.N., Lobo, A. and Greenland, S. (2017), “The influence of cultural values on green purchase behavior", Marketing Intelligence and Planning, Vol. 35 No. 3, pp. 377-396.

Parkinson, J., David, P. and Rundle-Thiele, S. (2017), "Self-efficacy or perceived behavioral control: which influences consumers' physical activity and healthful eating behavior maintenance?", Journal of Consumer Behavior, Vol. 16, pp. 413-423.

Punyatoya, P. (2015), "Effect of perceived brand environment-friendliness on Indian consumer attitude and purchase intention: an integrated model", Marketing Intelligence and Planning, Vol. 33 No. 3, pp. 258-275.

Scarpa, R., and Willis, K. (2010), "Willingness-to-pay for renewable energy: primary and discretionary choice of British households' for micro-generation technologies", Energy Economics, Vol. 32, pp. 129-136.

Sharma, P. (2010), "Measuring Personal Cultural Orientations: scale Development and Validation", Journal of the Academy of Marketing Science, Vol. 38, No. 6, pp. 787-806.

Soyez, K. (2012), "How national cultural values affect pro-environmental consumer behavior", International Marketing Review, Vol. 29 No. 6, pp. 623-646.

Srite, M., and Karahanna, E. (2006), "The role of espoused national cultural values in technology acceptance”, MIS Quarterly, Vol. 30, No. 3, pp. 679-704.

Steg, L., Bolderdijk, J.W., Keizer, K. and Perlaviciute, G. (2014), “An integrated framework for encouraging pro-environmental behavior: the role of values, situational factors and goals", Journal of Environmental Psychology, Vol. 38, pp. 104-115.

Tan, C-S., Ooi, H-Y. and Goh, Y-N. (2017), "A moral extension of the theory of planned behavior to predict consumers' purchase intention for energy-efficient household appliances in Malaysia”, Energy Policy, Vol. 107, pp. 459-471.

Tanner, C., and Kast, S.W. (2003), "Promoting sustainable consumption: determinants of green purchases by Swiss consumers", Psychology and Marketing, Vol. 20, No. 10, pp. 883-902. 
Thieme, J., Royne, M.B., Jha, S., Levy, M. and McEntee, W.B. (2015), "Factors affecting the relationship between environmental concern and behaviors", Marketing Intelligence and Planning, Vol. 33 No. 5, pp. 675-690.

Tonglet, M., Phillips, P.S., and Readc, A.D. (2004), "Using the Theory of Planned Behavior to investigate the determinants of recycling behavior: a case study from Brixworth, UK", Resources, Conservation and Recycling, Vol. 41, pp. 191-214.

Trivedi, R.H., Patel, J.D. and Savalia, J.R. (2015), "Pro-environmental behavior, locus of control and willingness to pay for environmental friendly products", Marketing Intelligence and Planning, Vol. 33 No. 1, pp. 67-89.

Vlek, C. and Steg, L. (2007), "Human behavior and environmental sustainability: problems, driving forces and research topics”, Journal of Social Issues, Vol. 63 No. 1, pp. 1-19.

Vroom, V.H. (1964), Work and Motivation, Wiley, Oxford.

Wang, S., Fan, J., Zhao, D., Yang, S. and Fu, Y. (2016), “Predicting consumers' intention to adopt hybrid electric vehicles: using an extended version of the theory of planned behavior model", Transportation, Vol. 43, pp. 123-143.

Wang, Z., Wang, X. and Guo, D. (2017), "Policy implications of the purchasing intentions towards energy-efficient appliances among China's urban residents: do subsidies work?", Energy Policy, Vol. 102, pp. 430-439.

Wang, Z., Zhang, B., Yin, J. and Zhang, Y. (2011), "Determinants and policy implications for household electricity-saving behavior: evidence from Beijing, China", Energy Policy, Vol. 39, pp. 3550-3557.

Wu, S.I., and Chen, J.Y. (2014), "A model of green consumption behavior constructed by the theory of planned behavior", International Journal of Marketing Studies, Vol. 6 No. 5, pp. 119-132. 
Figure 1. Conceptual framework of this study

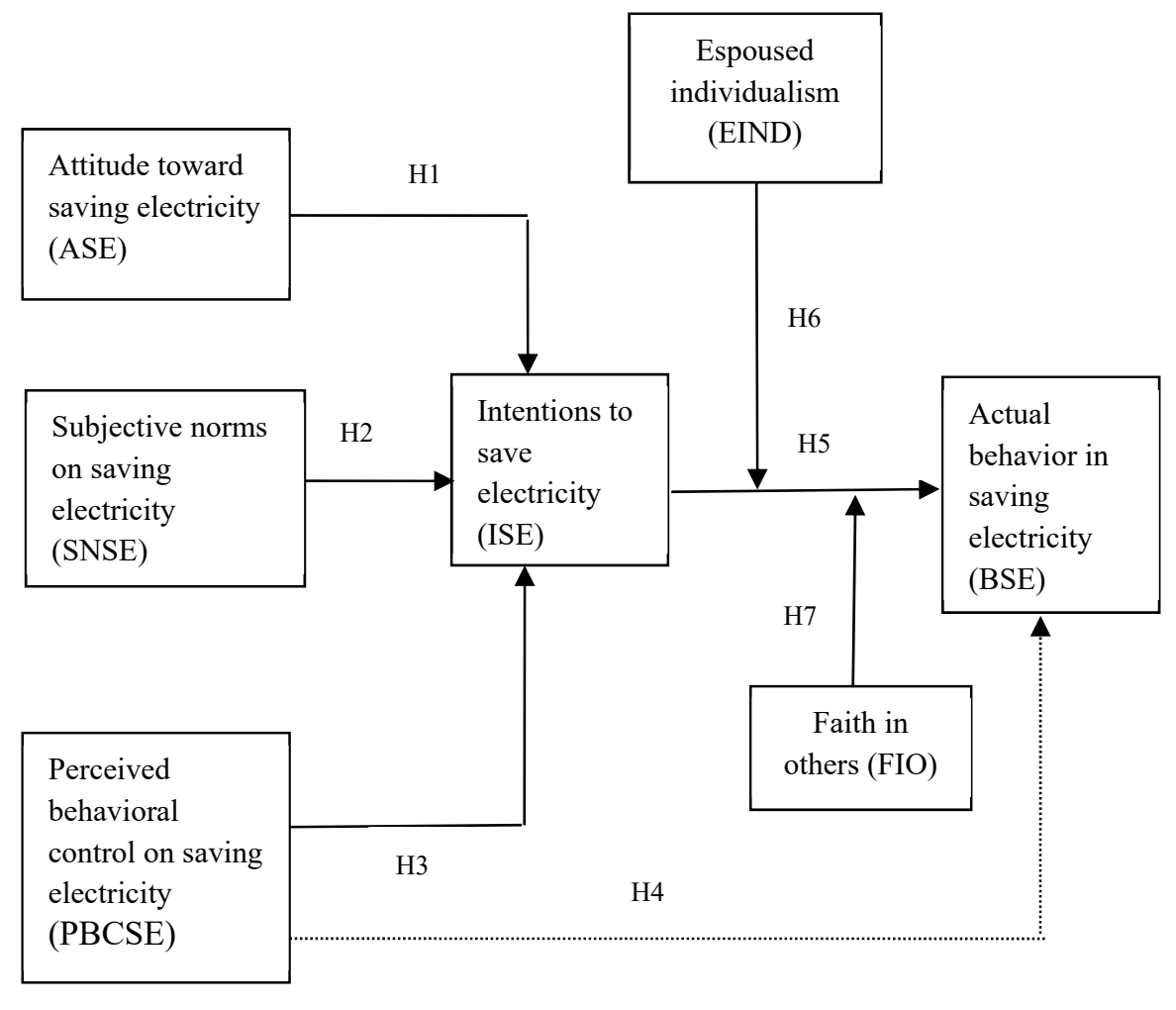


Table I. Scale items and descriptives of the variables

\begin{tabular}{|c|c|}
\hline Scale items & $\lambda$ \\
\hline \multicolumn{2}{|l|}{ Attitude toward saving electricity (ASE) } \\
\hline I (dislike $1 \ldots \ldots 2 \ldots 3 \ldots \ldots 4 \ldots 5 \ldots 6 \ldots .7$ like) the idea of saving electricity. & .86 \\
\hline Saving electricity is a (bad $1 \ldots . .2 \ldots .3 \ldots . \ldots 4 \ldots 5 \ldots . .6 \ldots 7$ good) idea. & .88 \\
\hline $\begin{array}{l}\text { I have a/an (unfavorable } 1 \ldots \ldots 2 \ldots \ldots 3 \ldots \ldots 4 \ldots . .5 \ldots 6 \ldots . .7 \text { favorable) attitude toward } \\
\text { saving electricity. }\end{array}$ & .88 \\
\hline $\begin{array}{l}\text { I have (weak } 1 \ldots \ldots 2 \ldots \ldots 3 \ldots . . .4 \ldots 5 \ldots \ldots 6 \ldots .7 \text { strong) belief that saving electricity } \\
\text { can save the environment }\end{array}$ & .77 \\
\hline \multicolumn{2}{|l|}{ Subjective norms on saving electricity (SNSE) } \\
\hline My family members think that I should save electricity in the coming month. & .81 \\
\hline My friends believe that I should save electricity in the coming month. & .96 \\
\hline $\begin{array}{l}\text { My classmates at college or colleagues at the office think that I should save } \\
\text { electricity in the coming month. }\end{array}$ & .90 \\
\hline \multicolumn{2}{|l|}{ Perceived behavioral control on saving electricity (PBCSE) } \\
\hline Whether or not I will save electricity in the coming month is entirely up to me. & .86 \\
\hline $\begin{array}{l}\text { I have complete control over the amount of electricity to be saved in the coming } \\
\text { month. }\end{array}$ & .97 \\
\hline $\begin{array}{l}\text { Whether or not I will save electricity in the coming month is completely within my } \\
\text { control. }\end{array}$ & .96 \\
\hline I am confident that I can save electricity in the coming month. & .89 \\
\hline \multicolumn{2}{|l|}{ Intentions to save electricity (ISE) } \\
\hline \multicolumn{2}{|l|}{ Over the next one month, } \\
\hline I intend to use less lighting because it save electricity. & .83 \\
\hline I plan to turn off the computer monitor when it is not in use. & .86 \\
\hline I will consider to turn on home entertainment only when required, e.g., TV. & .88 \\
\hline $\begin{array}{l}\text { I intend to reduce the use of electricity when using the electric items, e.g., electric } \\
\text { water heater. }\end{array}$ & .78 \\
\hline $\begin{array}{l}\text { I will consider to pre-set the air-conditioner to a comfortable energy-efficient } \\
\text { temperature. }\end{array}$ & .84 \\
\hline \multicolumn{2}{|l|}{ Espoused individualism (EIND) } \\
\hline $\begin{array}{l}\text { Having autonomy and independence is more important than being accepted as a } \\
\text { member of a group. }\end{array}$ & .77 \\
\hline Individual success is more important than group success. & .76 \\
\hline Individual gain is more important than loyalty to a group. & .86 \\
\hline \multicolumn{2}{|l|}{ Individual rewards are more important than group welfare. } \\
\hline \multicolumn{2}{|l|}{ Faith in others (FIO) } \\
\hline $\begin{array}{l}\text { Science and technology will come up with ways to solve environmental damage } \\
\text { and pollution. }\end{array}$ & .74 \\
\hline $\begin{array}{l}\text { The generation in school today will be more careful about the environment than } \\
\text { earlier generations. }\end{array}$ & .83 \\
\hline $\begin{array}{l}\text { Industry causes most environmental problems so it should pay for the clean-up and } \\
\text { prevention out of its profits. }\end{array}$ & .76 \\
\hline $\begin{array}{l}\text { It's time for the government to be more aggressive in its environmental protection } \\
\text { policy. }\end{array}$ & .75 \\
\hline \multicolumn{2}{|l|}{ Actual behavior in saving electricity (BSE) } \\
\hline \multicolumn{2}{|l|}{ For the past one month, } \\
\hline I turned off the lighting when & .77 \\
\hline I turned off the computer monitor when it was not needed. & .81 \\
\hline
\end{tabular}


I turned off my home entertainment system when it was not needed.

I switched off the electric water heater when it was not needed.

I switched off the air-conditioner when it was not needed.

Notes: $\lambda=$ Standardized factor loadings 
Table II. Correlations among the variables

\begin{tabular}{|c|c|c|c|c|c|c|c|}
\hline Construct & 1 & 2 & 3 & 4 & 5 & 6 & 7 \\
\hline 1. Attitude toward saving electricity (ASE) & .84 & & & & & & \\
\hline 2. Subjective norms toward saving electricity (SNSE) & $.36^{* *}$ & .89 & & & & & \\
\hline 3. Perceived behavioral control over saving electricity (PBCSE) & $.42^{* *}$ & $.70^{* * *}$ & .92 & & & & \\
\hline 4. Espoused individualism (EIND) & .02 & -.05 & .04 & .84 & & & \\
\hline 5. Faith in others (FIO) & $.63^{* * *}$ & $.30^{* *}$ & $.39^{* *}$ & .06 & .81 & & \\
\hline 6. Intentions to save electricity (ISE) & $.62^{* * *}$ & $.33^{* *}$ & $.34^{* *}$ & .03 & $.54^{* * *}$ & .78 & \\
\hline 7. Behavior to save electricity (BSE) & $.26^{* *}$ & $.18^{* *}$ & $.23^{* *}$ & .03 & $.23^{* *}$ & $.22^{* *}$ & .78 \\
\hline Mean & 5.87 & 3.63 & 3.33 & 4.33 & 5.49 & 5.41 & 5.45 \\
\hline Standard deviation & .96 & 1.45 & 1.59 & 1.22 & 1.04 & 1.09 & .96 \\
\hline Composite reliability (CR) & .90 & .92 & .96 & .82 & .72 & .84 & .81 \\
\hline Average variance extracted (AVE) & .71 & .80 & .85 & .70 & .65 & .61 & .61 \\
\hline
\end{tabular}

Notes: Figures on the diagonal represent the square roots of average variance extracted (AVE) for each construct. ${ }^{* *} p<.01 ;{ }^{* * *} p<.001$ 
Table III. Hypothesis testing results based on structural equation modeling

\begin{tabular}{clc}
\hline H\# & Hypotheses & $\boldsymbol{\beta}$ \\
H1 & Attitude $\rightarrow$ Intention to save electricity & $.58^{* * *}$ \\
H2 & Norms $\rightarrow$ Intention to save electricity & $.32^{* * *}$ \\
H3 & Control $\rightarrow$ Intention to save electricity & $.21^{* *}$ \\
H4 & Control $\rightarrow$ Behavior to save electricity & $.13^{*}$ \\
H5 & Intention to save electricity $\rightarrow$ Behavior & $.25^{* *}$ \\
H6 & Individualism * Intention $\rightarrow$ Behavior & $-.18^{*}$ \\
H7 & Faith in others * Intention $\rightarrow$ Behavior & $.14^{*}$ \\
& Control variables & -.03 \\
C1 & Age $\rightarrow$ BSE & .05 \\
C2 & Gender $\rightarrow$ BSE & .04 \\
C3 & Education $\rightarrow$ BSE & .07 \\
C4 & Income $\rightarrow$ BSE & \\
\hline Notes: & $\beta=$ Standardized regression coefficient ${ }^{*} p<.05 ;{ }^{* *} p<.01 ;{ }^{* * *} p<.001$
\end{tabular}

